\title{
LA MODERNIDAD ALIMENTARIA Entre la sobreabundancia y la inseguridad ${ }^{*}$
}

\author{
JESÚS CONTRERAS HERNÁNDEZ \\ Universidad de Barcelona
}

\author{
PALABRAS CLAVE ADICIONALES \\ ADDITIONAL KEYWORDS \\ Seguridadalimentaria, Alimentación, Percepciones \\ sociales, Consumo. \\ Food Safety, Food, Social Perceptions, \\ Consume.
}

RESUMEN. El presente del consumo alimentario en los países más industrializados parece caracterizarse por una importante paradoja. Por una parte, existe una oferta pletórica de alimentos que permite unas enormes posibilidades de opción. Además, a lo largo del siglo XX, la esperanza de vida al nacer se ha más que doblado. Asimismo, el conocimiento científico sobre los alimentos y sobre sus efectos en la biología humana son hoy mayores que nunca como lo es también la preocupación por la seguridad alimentaria y los medios empleados para obtenerla. Por otra parte, sin embargo, aparentemente, la preocupación de los ciudadanos sobre los alimentos que consumen es mayor que nunca y es del todo recurrente la pregunta sobre qué podemos comer sin miedo. Plantear esta paradoja y explicar las diferentes razones que permiten comprenderla son los objetivos de este artículo.

ABSTRACT. The food present of the most industrialized countries seems to be characterized by an important paradox. On the one hand, there exists a plethoric offer of food that allows a few enormous possibilities of option. Besides, throughout the XXth century, the life expectancy on having been born is more than doubled. Likewise, the scientific knowledge on the food and on his effects in the human biology are today major that since it is never also the worry for the food safety and the means used to obtain it. On the other hand, nevertheless, seemingly, the worry of the citizens on the food that they consume is major than never and it is completely an appellant the question what can we eat without fear? To raise this paradox and to explain the different reasons that allow to understand (include) it are the aims of this article.

\footnotetext{
"Este artículo responde a una investigación en curso titulada, "La percepción social de las crisis alimentarias" (Ministerio de Ciencia y Tecnología, EET 20002-05146).

E-mail: contreras@ub.edu
}

Revista Internacional de Sociología (RIS)

Tercera Época, No40, Enero-Abril, 2005, pp. 109-132. 
RIS

\section{INTRODUCCIÓN}

Después de siglos de malnutrición recurrente como consecuencia de una cierta falta de alimentos, hoy, en las sociedades industrializadas, se puede afirmar, salvo excepciones, que todo el mundo come y que se ha instalado un sentimiento de afluencia e incluso de sobreabundancia alimentaria. Tradicionalmente, hasta la década de los cincuenta, incluso sesenta, para las clases trabajadoras, una buena alimentación era, ante todo, una alimentación "nutritiva", es decir, "sana", pero sobre todo, abundante y saciante. Hoy, en cambio, la mayoría de la población piensa que "comemos demasiado". El "temor de que no alcance la comida" ha retrocedido. Hoy la preocupación dominante es cada vez más de carácter cualitativo. Desde los años ochenta, el término más a menudo empleado tanto por las madres de familia como por los dietistas para caracterizar una buena alimentación es el de equilibrio. En nuestros días, de acuerdo con Fischler (1995), en el espíritu de los comensales contemporáneos la cuestión crucial' es cada vez más saber qué comer y en qué proporción. La preocupación cuantitativa no está ausente, pero se plantea más bien en términos de restricción. Las encuestas muestran, en efecto, que, a cada instante, entre un cuarto y un quinto de la población sigue algún tipo de régimen.

Por otro lado, a lo largo de la historia de los hoy llamados países desarrollados, en ningún otro momento los seres humanos se habían encontrado tan bien de salud y durante tanto tiempo, como en la actualidad. De hecho, todos los datos apuntan en la misma dirección: nunca en la historia de las sociedades occidentales, la población había tenido tanto que comer ni había estado tan libre de las hambrunas o de la escasez como hasta ahora, y nunca, tampoco, había alcanzado una esperanza de vida tan alta. En efecto, a lo largo del siglo XX en España la esperanza de vida al nacer se ha más que duplicado pasando de 34,7 años en 1900 a 77,5 en el año 2000. Sin embargo, si se confronta esta realidad de la situación de la salud con el estado nutricional de la sociedad y, sobre todo, con la opinión que se percibe, se llega a imágenes totalmente diferentes. Aparentemente al menos, los cambios que se han producido en los regímenes alimentarios de la mayoría de países del mundo ponen de manifiesto, en lugar de la abundancia y del bienestar, una cierta mala nutrición. En las sociedades industrializadas, una vez se ha resuelto el problema de garantizar el nivel de subsistencia, el interés se centra en saber si su alimentación, elegida más o menos libremente y entre numerosas opciones, resulta fiable en términos de calidad y de inocuidad. En efecto, hasta mediados del siglo XX, cuando se hablaba de seguridad alimentaria era para referirse a garantizar el aprovisionamiento. En los últimos años, sin embargo, el término de seguridad alimentaria ha adquirido otro significado. En los países más industrializados, por este término se está entendiendo el consumo de alimentos libres de riesgos para la salud. Esta segunda acepción se explica, quizás, por el hecho de que, cada vez más, las sociedades toman precauciones para minimizar los posibles peligros asociados a los alimentos, tales como la intoxicación o la contaminación. Para 
ello se recomiendan medidas de evitación, se investiga y se aplican técnicas de manipulación específica, de conservación, etc.

También, por otro lado, nunca como hoy habíamos sabido tanto sobre los alimentos, sobre las enfermedades y sobre la biología y la fisiología humanas. Los avances científicos y tecnológicos desarrollados a lo largo de las últimas décadas permiten unos tipos de análisis extraordinariamente pormenorizados, de tal manera que de cualquier alimento o producto puede expresarse su composición cualitativa y cuantitativa hasta el mínimo detalle. De este modo, y a juzgar por las publicaciones científicas, por su eco en los medios de comunicación e, incluso, por la publicidad alimentaria, nuestra sociedad contemporánea no parece ya que coma manzanas, carne de pollo o de cerdo, atún, coliflor, pan, yogur o que beba vino o cerveza, sino calcio, hierro, polifenoles, flavonoides, vitamina tal o cual, carotenoides, glucosinolatos, fibra, ácidos grasos, licopeno, esteroles, ácido oleico, fósforo, alcohol etílico, etc. Las categorías relativas a los alimentos parecen haberse modificado considerablemente en el sentido de una mayor "cientifización". Al mismo tiempo que conocemos mejor la composición de los productos alimentarios, también conocemos cada vez más y mejor los efectos de los diferentes nutrientes o sustancias sobre nuestro organismo. Consecuentemente con todo ello, hoy, los científicos, los responsables de la sanidad pública y las industrias agroalimentarias nos recomiendan con más precisión y con más convencimiento qué es lo que debemos ingerir para estar sanos y para prevenir las diferentes enfermedades. Veamos algunos ejemplos:

RECOMENDACIONES CUANTITATIVAS DE CONSUMO
DE ALGUNOS ALIMENTOS SEGÚN "ESTUDIOS CIENTÍFICOS"

Q El C.S.I.C. recomienda beber hasta un litro de cerveza a la semana por razones de salud. DTomar hasta seis copas de vino a la semana protege contra el derrame cerebral. पComer un huevo al día no supone un mayor riesgo para el corazón. QUn adulto sano debe ingerir un mínimo de medio litro de leche al día. $\mathrm{DEl}$ consumo diario de yogur retrasa la aparición de ciertos tumores. TEtc., Etc.

CORRELACIONES PROBABILISTAS ENTRE
ALIMENTACIÓN Y SALUD-ENFERMEDAD
s personas que toman entre 1 y 6 vasos de vino semanales reducen el riesgo de sufrir
prejia en un $34 \%$.
pino puede reducir en un $19 \%$ el riesgo de degeneración macular.
n consumo diario de 2 o 3 tazas de té reduce hasta un $46 \%$ el riesgo de padecer arteriosclerosis
la aorta.


RIS

En definitiva, podría pensarse, pues, que nunca como ahora habíamos comido tanto, $\tan$ variado y mejor. Nunca, como ahora, habíamos estado tan saciados. Nunca, como ahora, habíamos vivido tanto, tan variado y mejor. Nunca, como ahora, habíamos tenido tantos controles alimentarios, tecnologías tan eficientes y sofisticadas para garantizar la seguridad (inocuidad) de nuestros alimentos; unas autoridades, unos científicos, unos medios de comunicación y unas organizaciones de consumidores tan preocupados por nuestro bienestar. Es decir, nunca había existido tanta seguridad alimentaria. Y, sin embargo, la "inseguridad" no desaparece e, incluso, aumentan las incertidumbres y las dudas acerca de lo que comemos y de los posibles riesgos ${ }^{1}$ que puede entrañar nuestra comida, es decir, los daños potenciales/probables para nuestra salud. Es decir, tampoco nunca como ahora habíamos estado tan preocupados por nuestra salud y nuestra alimentación. Según el CREDOC (2002), si en 1997 el 35\% de los franceses opinaba que los productos alimentarios presentaban algunos riesgos para la salud y el $20 \%$ decía que presentaban riesgos importantes, tres años después, en 2000, estas valoraciones se habían hecho más negativas, aumentando al $40 \%$ y al $30 \%$, respectivamente. Parece ser, pues, que cada vez una mayor cantidad de población tiene más dudas acera de la inocuidad alimentaria. ¿Por qué? La respuesta es compleja y exige analizar el proceso de transformaciones ocurridas en todas y cada una de las fases de la cadena alimentaria, así como en las actitudes, representaciones y percepciones sociales relativas a los alimentos.

\section{LA GLOBALIZACIÓN DE LOS REPERTORIOS ALIMENTARIOS}

Los sistemas alimentarios han pasado en poco tiempo de unos ecosistemas muy diversificados a otros hiperespecializados e integrados en vastos sistemas de producción agroalimentaria a escala internacional. De este modo, ha aumentado considerablemente la producción mundial de alimentos, al tiempo que han desaparecido numerosas variedades vegetales y animales que habían constituido la base de dietas de ámbito más o menos localizado. Asimismo, paralelamente a este proceso, las tareas de la cocina doméstica han sido transferidas, en gran medida, a la industria. Como consecuencia de todo ello, cada vez se consume una mayor cantidad de alimentos procesados industrialmente. Este fenómeno no tiene lugar

\footnotetext{
${ }^{1}$ Las percepciones y representaciones del riesgo en relación con los alimentos ha sido objeto de numerosos estudios (Steemkamp, 1990; Poulsen, Juhl, Kristensen, Bech y Engelund, 1996; Grunert, Larsen, Madsen y Baadsagaard, 1996), proporcionando bases útiles para analizar las crisis alimentarias y el grado de confianza de los consumidores en la seguridad de los alimentos y en la eficacia de los controles.
} 
sólo en los países más industrializados, sino, también, aunque con concreciones, matices, grados y consecuencias diferentes, en todos los países del mundo. Todo ello ha supuesto una ampliación del repertorio alimentario, a la vez que una homogeneización del mismo. Hoy, en cualquier país del mundo, lo esencial de su alimentación proviene de un sistema de producción y de distribución cuya escala es planetaria.

Los comportamientos alimentarios en los países industrializados están hoy más basados en las estrategias de marketing de las empresas agroalimentarias que en la experiencia racional o en las prácticas tradicionales (Abrahamsson, 1979). Estas estrategias tienen una dimensión multinacional y/o global y afectan también a los países del Tercer Mundo, donde los mayores o menores efectos dependen de la medida en que las diferentes comunidades se incorporan a una economía monetaria. En estos países los cambios que se introducen en los modos de producción suponen una menor dedicación de la tierra y el trạbajo a la producción de subsistencia, y mayor a los cultivos comerciales (Manderson, 1988: 179).

Las grandes empresas agroalimentarias controlan cada vez más los procesos de producción y distribución de alimentos; unos alimentos, por otra parte, producidos cada vez más industrialmente y ello a pesar de que la noción misma de "industria alimentaria" (Atkinson, 1983: 10-16; Fischler, 1979: 201) resulta repugnante a mucha gente. En efecto, el consumo de alimentos procesados ha aumentado considerablemente en los últimos treinta años; y sigue haciéndolo a pesar de sus detractores morales, gastronómicos, económicos y dietéticos, tanto en los países más industrializados como en los del Tercer Mundo. Aumenta el consumo de dichos productos en cantidad de unidades, en diversidad de productos y en porcentaje de presupuesto. El proceso está lejos de ver su punto final porque la tecnología alimentaria está diseñando constantemente nuevos productos y las últimas aplicaciones alimentarias de la biotecnología anuncian numerosas novedades para un futuro más o menos inmediato, tales como, por ejemplo, tomates que no se pudren, leche de vaca con vacunas incorporadas, berenjenas blancas, arroces colorados y aromatizados, patatas con un almidón de mejor calidad que las hará más crujientes una vez fritas, maíz con un leve sabor a mantequilla, etc.

En definitiva, hoy en día, los países industrializados pueden disponer de una mayor variedad de alimentos a lo largo del año. Es cierto, también, que, para que esto haya sido posible, se ha tenido que recurrir (para permitir la conservación $\mathrm{y}$ el transporte) a un uso generalizado y creciente de aditivos (conservantes, colorantes, aromatizantes, etc.). Estos aditivos contribuyen, también, por una parte, a una homogeneización progresiva de los alimentos, y, por otra, suponen una ingestión sistemática y prolongada de sustancias cuyas consecuencias no son todavía bien conocidas.

La evolución de los modos de vida hacia actividades menos productivas está en el origen de estos procesos. El aumento del nivel de vida, asociado a un desarrollo del salario, así como a una evolución del lugar y del papel social de 


\section{RIS}

las mujeres, comportó un traspaso de la producción doméstica alimentaria hacia el sistema de mercado. Todo ello se tradujo en una regresión del autoconsumo, en una demanda creciente de productos listos para comer y en un aumento de la frecuentación de las diversas formas de restauración. Asimismo, la individualización creciente de los modos de vida ha comportado una cierta desritualización de las tomas alimentarias, reforzada por la disminución de las influencias religiosas y morales. La convivialidad asociada a las comidas ha perdido importancia. Ha aumentado la diversidad de los tipos de tomas alimentarias según los contextos (lugares, momentos, convivios...) y, como consecuencia, ha aumentado el abanico de expectativas relativas a las características cualitativas de los productos alimentarios (Lambert, 1997: 55).

\section{RUPTURAS EN LOS SISTEMAS DE REPRESENTACIÓN ALIMENTARIOS Y DESCONFIANZA DE LOS CONSUMIDORES}

La revolución industrial aplicada a la industria alimentaria ha permitido en las últimas décadas incrementar considerablemente la disponibilidad de todo tipo de alimentos, hasta el punto de que, como ya hemos dicho, se ha pasado de la escasez a la sobreabundancia. Éste es el aspecto positivo de dicha revolución, pero hay otros. Como ha señalado Fischler $(1979,198-200)$, en pocas décadas la revolución industrial, la especialización y los rendimientos crecientes de la producción agrícola y el desarrollo hipertrófico de las ciudades, entre otras cuestiones, todo ello ha contribuido a crear una "modernidad alimentaria" que ha trastocado o, incluso, subvertido, la relación del hombre con su alimentación. Con la evolución de la producción y de la distribución agroalimentaria se ha perdido progresivamente todo contacto con el ciclo de producción de los alimentos: su origen real, los procedímientos y las técnicas empleadas para su producción, su conservación, su almacenamiento y su transporte. Los consumidores sólo tienen un conocimiento parcial de esta evolución, que va desde lo que podríamos llamar la situación tradicional o pre-industrial, hasta la actual era del cracking y el ensamblaje. Gruhier (1989) ha llegado a decir que los animales que hoy consumimos (también los vegetales) son auténticos mutantes que tienen poco que ver con sus antepasados de hace tan sólo 30 o 40 años, mientras que el hombre contemporáneo, biológicamente al menos, se parece como dos gotas de agua a su antepasado medieval. En este cuadro evolutivo, el rol de las industrias alimentarias ha cambiado y el alimento se presenta de una manera dual. Por una parte, se vuelve artificial, y, por otra, debe conservar un estatus "natural", pues éste es el único nexo tangible con la naturaleza para el consumidor. Así pues, si bien con el tiempo las prácticas alimentarias pueden ser evolutivas, el cambio parece tropezar con la insatisfacción del consumidor, confrontado, por ejemplo, a los alimentos industriales, que los encuentra insípidos, faltos del sabor e, incluso, peligrosos. 
Ahora bien, mientras que los alimentos habrían cambiado mucho durante estos últimos 40 años, su simbología, o sus representaciones sociales, se caracterizarían por una mayor duración o continuidad. En efecto, los sistemas de representaciones de los consumidores están evolucionando más lentamente que los sistemas de producción-distribución con sus innovaciones tecnológicas relativas tanto a los productos como al empaquetado, y tanto a los lugares de producción como al transporte, al almacenamiento y a la distribución. Todo ello obliga a interrogarse por el futuro de las categorizaciones implícitas que condicionan los gustos y los rechazos alimentarios (Maho y Pinson, 1989: 202). Por ejemplo, desde un punto de vista organoléptico, no sólo los gastrónomos se interesan por la compatibilidad entre la tecnología alimentaria y el mantenimiento del sabor propio de cada tipo de alimentos. Los consumidores tienen la sensación de que la tecnología ha estado exclusivamente al servicio del productor, del transportista, del vendedor (rendimiento, crecimiento rápido, aspecto atractivo, conservación, etc.), pero no al servicio de sus papilas.

“... veamos lo que ha ocurrido después de veinte años con las frutas y legumbres: se han vuelto insípidas y sin gran interés gustativo. En efecto, se han efectuado las selecciones sobre una cantidad de criterios favorables al productor, al transportista y al vendedor: rendimiento, solidez del fruto, posibilidad de cosecha precoz o mecanizada, actitud para la maduración artificial, color y aspecto ventajoso, etc. (...) ¿Los buenos tomates son los hinchados? ¿Los mejores guisantes son extrafinos? ¿Los melocotones blancos son los exquisitos? Entonces, se seleccionan los tomates bajo el criterio de la hinchazón, los guisantes bajo el de la finura, los melocotones bajo el de la blancura, sin ocuparse jamás del sabor. Resultado: melocotones blancos pero sin gusto, tomates hinchados pero insípidos, guisantes extrafinos y harinosos.Y todo en consonancia: malas judías verdes pero sin hilos, fresas sin perfume a pesar de su crujiente rojo carmín, manzanas rojas pero no maduras..." (Gruhier, 1989: 77).

Asimismo, con la llamada cocina industrial, ni la composición ni la forma de los alimentos evocan un significado preciso y familiar; antes al contrario, puede evocar ya cualquier cosa, como, por ejemplo, "carne en bastoncitos" o "palitos de cangrejo". Así, el riesgo mayor que parece plantear la modernidad alimentaria se refiere a la incapacidad de los consumidores modernos para clasificar los productos de la industria alimentaria (Ariès, 1997). Entre la tecnología, por una parte, y el marketing y la publicidad, por otra, habrian sido destruidas las referencias culturales de la alimentación. El alimento se habría convertido en un objeto sin historia conocida, y el consumidor moderno no sabría ya qué es lo que realmente está comiendo (Fischler, 1979: 202).

Con la multiplicación de las elecciones gustativas alimentarias, es necesario considerar que el consumidor hoy no es más que un conocedor parcial de la variedad de los gustos o sabores de los alimentos cuyas cualidades organo- 
RIS

lépticas y microbiológicas se mejoran. El espaciamiento entre la repetición de una misma experiencia alimentaria hace más difícil la memorización de los sabores particulares y la constitución de una memoria gustativa personal. Asimismo, la posible confusión en relación con las representaciones alimentarias puede afectar a las imágenes sobre los sistemas de producción, así como a elementos como los lugares de aprovisionamiento y los sistemas de distribución.

Hoy, la naturaleza cada vez más artificial de la alimentación suscita problemas en el consumidor. Provoca una ruptura con las reglas ancestrales, pero también la oportunidad de hacer evolucionar el perfil del comensal hacia un individuo consciente de su pasado cultural, autónomo (libre de sus elecciones alimentarias en la abundancia de la oferta), responsable (formado en el conocimiento de las características de los alimentos) y promotor de su propia riqueza alimentaria. Fischler (1990) muestra que la ausencia de consenso implícito o explícito unívoco sobre el arte y la manera correcta de alimentarse comporta para el comensal una gran incertidumbre y una verdadera ansiedad. Además, el desconocimiento de los modos de fabricación de los alimentos y de la o las materias primas utilizadas se añade a esta confusión, desarrollándose entre los consumidores una actitud de desconfianza hacia la oferta alimentaria, más pletórica que nunca. Resulta fundamental la familiarización en la aceptación de los alimentos nuevos. Sylvander y Melet (1994) evocan "la incertidumbre sobre las definiciones de los productos", sobre "la calidad de los productos", que estaría en el origen de un aumento de la desconfianza de los consumidores constatada desde los años 60 , así como del desarrollo de políticas de gestión de calidad en las empresas. Del complejo sistema internacional de producción y distribución alimentaria, los consumidores sólo conocen los elementos terminales: los lugares de distribución y los productos. El resto es una verdadera caja negra, que entraña un miedo tanto más grande en la medida en que la subsistencia está asociada a la alimentación.

Los productos alimentarios disponibles son identificados por los individuos si sus características percibidas físicamente por sus órganos sensoriales tienen un sentido, un significado, encontrado por el cerebro en el sistema de representaciones pre-establecido. Los consumidores resumen su percepción por ideas sobre la autenticidad y la calidad. Ello significa la perfecta adecuación a su cultura, a su sistema de representaciones. La menor separación de tales productos con relación a esta cultura puede hacerle perder su sentido hasta el punto de que no parezcan verdaderos alimentos, sino que parezcan pastiches, artefactos, "plástico", que "no tienen alma". En este sentido, el diseñador Jegou (1991) precisa que "la industria proporciona un flujo de alimentos sin memoria" en el que la dimensión simbólica de la alimentación ya no es el resultado de un lento proceso de sedimentación entre el hombre y su alimento, sino que le preexiste. Así, los "nuevos alimentos" pueden ser clasificados en el límite de lo comestible y su ingestión se supone llena de riesgos. Asuntos muy destacados por los medios de comunicación (la crisis de 
las "vacas locas", por ejemplo) refuerzan claramente esta ansiedad latente. Los nuevos productos poseen por esencia elementos exteriores a la cultura de la casi totalidad de los individuos a los cuales les son presentados (Lambert, 1997: 57-58).

La cultura alimentaria hoy dominante no parece haber integrado en su seno el nuevo contexto de producción-distribución caracterizado por una agricultura muy mecanizada que proporciona las materias primas a unas industrias que, a su vez, proceden de transformaciones cada vez más sofisticadas y venden a las grandes superficies los productos ya empaquetados. En el sistema actual de representaciones, el universo de lo comestible está constituido por alimentos procedentes del sector primario, es decir, productos brutos y frescos con una imagen mental de naturaleza y en oposición a otros productos procedentes del sector industrial que formarían el universo de lo no-comestible. La percepción actual de los productos alimentarios parece que continúa elaborándose a partir de este doble universo de representaciones, puesto que la mayoría de las personas encuestadas al respecto consideran que "los productos industriales son menos buenos que los productos naturales" (Lambert, 1996:157-158).

En definitiva, la llamada "artificialización" de la alimentación y el desconocimiento respecto de los modos de fabricación de los alimentos y de las verdaderas materias primas utilizadas en su elaboración, provocan en el consumidor moderno una considerable incertidumbre, desconfianza y ansiedad. Incluso la noción de "granja factoría" resulta repugnante para muchas personas. En cierta medida, esta repugnancia deriva de diferentes tipos de repulsión hacia los tratamientos "inhumanos" a los que son sometidos los animales. Del mismo modo, la agroindustria es vilipendiada al ser vista como una derrochadora de los recursos naturales y basada en el uso de fertilizantes químicos "artificiales" (Atkinson, 1983: 16). Por todo ello, no ha de resultar extraño que los principales retos a los que hoy debe hacer frente la investigación y la industria agroalimentaria sean, precisamente, los de resolver los problemas que la propia industria ha generado en los consumidores y que pueden resumirse en la necesidad de restablecer la confianza y la seguridad en la inocuidad sanitaria de sus propios productos (ya sea con respecto a las consecuencias que su ingesta pueda tener en el consumidor como con respecto a las que su producción pueda tener en el medio ambiente) y en su calidad organoléptica.

\section{UN CASO PARADIGMÁTICO. Las "vacas locas"}

Con la globalización, las intoxicaciones alimentarias dejan de ser locales para pasar a ser internacionales. Una red de intercambios a escala planetaria y los sistemas de distribución en masa que proponen al consumidor atiborrado de enormes cantidades de mercancías provocan que la industria alimentaria sea muy sensible a los pánicos. En efecto, en estos sistemas hipercomplejos en los que participan sin dominarlos, los consumidores desorientados escuchan todos los rumores nega- 
RIS

tivos de envenenamiento, a menudo lanzados sin discernimiento por una prensa sensacionalista que privilegia el gran titular alarmante. Los pánicos alimentarios se multiplican provocando reacciones a menudo desordenadas por parte de las autoridades. Minorías influyentes manipulan los temores de los consumidores. Abundan los ejemplos: la llamada "octavilla de Villejuif" sobre los riesgos cancerígenos de los aditivos alimentarios; las amenazas de envenenamientos masivos e indiscriminados como forma de protesta política; las amenazas de envenenamiento de alimentos como chantaje económico a empresas alimentarias, etc. En cualquier caso, la complejidad creciente del sistema alimentario y mediático actual contribuye a incentivar un número cada vez mayor de pánicos alimentarios que mezclan lo imaginario y lo real (Campion-Vincent, 1994: 89-92).

No siempre la información proporcionada al consumidor para prevenir y superar sus temores resulta suficiente o adecuada. Dice Lambert (1997) que algunas informaciones sólo pueden'modificar la cultura de los individuos de un modo muy marginal porque, sobre todo, la desconfianza del consumidor es un estado afectivo primario ligado a su instinto de supervivencia y no se modifica con un simple razonamiento. Además, los consumidores europeos no parecen admitir ningún tipo de especulación con los riesgos para su salud derivados del consumo de cualquier tipo de producto alimenticio. Sin embargo, la prensa diaria informa regularmente de peligros derivados de las aplicaciones industriales de la investigación agroalimentaria. Un ejemplo reciente extraído de la prensa española:

"El uso abusivo de los antibióticos en el sector ganadero plantea una amenaza creciente a la salud de los consumidores, según han advertido ochenta expertos reunidos la pasada semana en Berlín a instancias de la Organización Mundial de la Salud. El abuso de antibióticos (...) acelera la proliferación de cepas de bacterias resistentes a los antibióticos. Aunque la ingestión de estas bacterias no suele tener consecuencias para la salud, puede causar graves enfermedades $-\mathrm{y}$ a veces incluso la muerte- en un pequeño número de consumidores. El hecho de que las bacterias sean resistentes a los antibióticos no hace sino dificultar el tratamiento de los pacientes" (Corbella, J.: La Vanguardia, 22-10-1997, p. 25).

Este tipo de consideraciones en forma de noticias o de artículos es muy frecuente, como lo es, también, la imposición de multas por alimentación indebida de los animales destinados al consumo humano de carne. Dentro de un contexto así, estalló en 1996 la denominada crisis de las "vacas locas", que gozó de un extraordinario seguimiento por parte de los medios de comunicación de numerosos países y que fue reeditado, con creces, en su segunda edición, la del 2000-2001. En buena medida dicha crisis contribuyó a reforzar la desconfianza y la ansiedad de los consumidores respecto de los productos cárnicos. Puede decirse que la llamada crisis de las "vacas locas" permitió descubrir algunos aspectos de la mencionada 
caja negra relativa a la cadena de producción de la carne de vacuno. Una cadena muy cerrada y en la que prácticamente se aprovechaba todo. El problema residía, de hecho, en la fabricación de carnes separadas mecánicamente, es decir, en la carne recogida sobre el armazón (pieza en canal) una vez que ha sido limpiado de los trozos de carne noble y de sus vísceras. Para fabricar estas carnes se utilizan columnas vertebrales sobre las cuales se extraen los residuos de carne, de tal manera que el proceso de recuperación comporta, también, los otros tejidos que puede estar pegados, como el sistema nervioso central. Estas partes estaban destinadas a ciertas preparaciones a base de carne (raviolis, hachis parmentier, hamburguesas, etc.). Los ingleses prohibieron esta práctica en diciembre de 1995. Previamente, en 1989, habían prohibido para el consumo humano ciertos despojos: el cerebro, la médula espinal, el intestino, el bazo, etc. Por otra parte, no fueron tanto las harinas cárnicas las que fueron prohibidas (en cualquier caso no se prohibió su exportación), sino las proteínas de rumiantes en la alimentación de rumiantes. Así, se planteaba el problema de la definición de la carne, de tal manera que esta palabra no cubre la misma realidad para el consumidor que para los industriales (Savey, 1997).

Las reacciones frente a la "vaca loca" se inscriben dentro de las tendencias de cambios observadas después de los años 80 . Las estadísticas de consumo de carnes posterior a la crisis de las "vacas locas" mostraron un descenso en el consumo de carnes bovinas aunque compensado parcialmente por el consumo de otras carnes y de pescados. Asimismo, se han desarrollado comportamientos completamente vegetarianos. Estos cambios de comportamiento encontraron su punto culminante en los momentos de auge en los medios de comunicación y, luego, se ralentizaron. Estas mismas reacciones se repitieron en las "crisis" del 2000-2001. En cualquier caso, parece también que un buen número de consumidores ha modificado profundamente sus actitudes.

La amplitud y virulencia de las reacciones están, sin duda, ligadas al cúmulo de elementos de la situación. En primer lugar, el desconocimiento del "prion", reconocido por los científicos, es fuente de ansiedad como todos los fenómenos desconocidos, y la idea de que este "agente" pueda penetrar en el cerebro y hacerle perder sus capacidades no puede ser más que enloquecedora, sobre todo teniendo en cuenta que los efectos no son inmediatos, sino a plazo desconocido. En segundo lugar, la transgresión de las leyes de la naturaleza (transformar un herbívoro en carnívoro) se integra difícilmente en la cultura de la mayoría de individuos y puede hacer peligrar la integración de su carne en el universo de lo comestible (Lambert, 1977: 243). En tercer lugar, el hecho de que la carne ocupe todavía un lugar central en la mayoría de los hogares populares de los países europeos es un tema de la máxima importancia (Cazes-Valette, 1997). En cuarto lugar, el papel desempeñado por los medios de comunicación de masas contribuye a aumentar los temores 
RIS

más que a disminuirlos ${ }^{2}$. En este sentido, como dice Savey (1997), los medios de comunicación son, en general, incapaces de tratar los problemas complejos y de movilizar el conocimiento al ritmo en que difunden las noticias; sus informaciones no pueden describir correctamente las realidades evolutivas y complejas, y no pueden, por tanto, evitar el participar en manipulaciones como las que han tenido lugar durante las crisis de las "vacas locas". Los medios de comunicación juegan en este tipo de crisis un rol esencial: dado su poder de sugestión, participan, tanto si quieren como si no, en su evolución. A la vez informadores del público y actores en tanto que informadores, los medios de comunicación deben poder contribuir a poner en perspectiva en el tiempo y en el espacio los acontecimientos que sufrimos como consumidores de informaciones.

En definitiva, como ha señalado Rèmond-Gouilloud (1997: 127-128), la crisis de las "vacas locas", al revelar la "cosificación" del mundo viviente, suscita una repulsión frente a la racionalidad productivista aplicada al mundo animal. $\mathrm{La}$ relación íntima que une a los seres vivos, desde ahora patente, indiscutible, invita a profundizar en la relación entre el hombre y su contexto natural y, en el plano jurídico al menos, a revisar el tratamiento. El medio, rito de pasaje hacia este orden refundado, ha cumplido bien su papel en la vanguardia de los interrogantes de nuestro tiempo. Sin embargo, a la hora de traducir esta constatación en la acción-es decir, en términos de derechos y deberes-la vida conceptual sorprende. Mientras que en otros lugares, o antaño, los animales sagrados o divinizados expresaban cada uno un valor utilitario o simbólico, la racionalidad judeo-cristiana, borrando este aparejamiento sutil, los ha relegado a todos a la categoría informe de las cosas. De repente, parece incongruente que el tigre más hermoso del mundo y el perro más fiel no sean más que una piedra; la única diferenciación parece sostenerse en la sensiblería y en los caprichos humanos y oscilando entre la categoría de lo perjudicial y la de especies protegidas. El pensamiento legislativo se reforma y reconoce al animal como un ser sensible y con derechos. Así, para Rèmond-Gouilloud, la monstruosidad no es que la vaca sea loca, sino que sea el hombre quien la enloquezca. En España, desde el 1 de octubre de 2004, el Código Penal tipifica como delito el "maltrato de animales domésticos".

Algunas reacciones "nacionales" y/o "nacionalistas" a la crisis de las "vacas locas" pueden proporcionarnos algunas claves para valorar la dimensión cultural

\footnotetext{
${ }^{2}$ En 1996, Lancet publicó un artículo, de origen francés, afirmando que los monos alimentados con harinas de carne presentaban una encefalopatía parecida a la enfermedad de Creutzfeldt-Jacob. Este artículo tuvo una enorme repercusión mediática. En el mismo momento, en Gran Bretaña, Mme Baker, especialista en estas enfermedades, dispone de una colonia de ouistitis alimentada con harina de carne desde hace quince años y declara no haber encontrado ningún caso sobre un centenar de individuos. Lo publicó y una discusión en Lancet ponía en duda las conclusiones del primer artículo francés, pero ningún medio de comunicación se hizo eco.
} 
existente en el consumo de carne en la actualidad. Cazes-Valette (1997, 210-211), evocando las nociones de etnocentrismo y de xenofobia de C. Lévi-Strauss, y más concretamente la actitud de repudio hacia las formas culturales que resultan alejadas de aquéllas con las cuales nosotros nos identificamos, y que se inscriben en las fronteras de la tribu o del grupo lingüístico, afirma que puede comprenderse que, algunos franceses, despreciando toda distancia científica, se contentaran con la mención VF (Viande Française) para tranquilizarse frente a la amenaza de las "vacas locas". El enemigo está en el extranjero (en este caso, Inglaterra). En España, pocos meses después del primer estallido de las "vacas locas", en diciembre de 1996 se aprobó una nueva Indicación Geográfica Protegida (la Ternera Gallega), cuyos folletos de propaganda decían así:

"Ternera gallega: la carne con carné. La $1^{\text {a }}$ carne de vacuno con Control Integral y Certificado de Garantía. El Consejo Regulador de Ternera Gallega ampara exclusivamente reses nacidas, criadas y sacrificadas en Galicia. Nuestras razas, nuestro clima que propicia excelentes forrajes y el peculiar manejo de los animales por los labradores gallegos, hacen esta carne única y apreciada en toda Europa. Con fecha 17 de diciembre de 1996 y mediante el Reglamente (CE) n 2400/96 la Comisión declara que Ternera Gallega merece ser inscrita en el Registro de Indicaciones Geográficas Protegidas y, por lo tanto, protegida a escala comunitaria como tal. Ternera Gallega, un producto con historia".

Se trata de otra manifestación del etnocentrismo alimentario. Lo propio, lo gallego en este caso (que podría equivaler a español), es un producto conocido, "tiene historia" y "carné" (es decir, "identidad") y, en esa medida, está controlado y, por esta razón, parece no entrañar peligro. Lo que ocurre es que la industrialización, como se ha dicho, ha provocado la pérdida de referencias, pero los consumidores siguen teniendo necesidad de ellas. A falta de otras referencias relativas al lugar de producción, a las materias primas, a las técnicas de manipulación o a la comprensión precisa de las informaciones que los productores suministran en relación a todo ello, la "marca" aparece como una nueva y posible "seña de identidad" que pretende conferir seguridad, confianza. Sin embargo, en el caso de las carnes, a falta de "marcas" productoras, proliferan las "Denominaciones de Origen" o las "Indicaciones Geográficas Protegidas", o bien las marcas de los establecimientos expendedores, las de las Grandes Cadenas de Distribución. Asimismo, marcas colectivas del tipo "Etiqueta Roja de Calidad" o "Agricultura Biológica" o "Agricultura Ecológica" permiten salir de la masa indiferenciada de las carnes anónimas a los productos sobre los cuales una entidad se compromete en la transparencia sobre determinados criterios de los cuales uno de los más importantes es el origen o la identidad de los productos. Todo ello podría explicar, según Cazes-Valette (1997, 222-223), que este tipo de marcas o etiquetados disminuyeran menos sus ventas de carnes con motivo de la "crisis de las vacas 
RIS

REVISTA INTERNACIONAL DE SOCIOLOCIA

№ 40, ENERO-ABRIL, 2005

JESÚS CONTRERAS HERNÁNDEZ

locas", que las que no tenían la "marca", pues, además de su papel jurídico de protección, la marca marca el producto, lo señala, lo identifica, y constituye un compromiso por parte de "su autor" (garantiza una constancia), una mejora de la oferta que es promovida como diferenciada y diferenciable de las ofrecidas por los concurrentes. Una marca reconocida inspira más confianza.

\section{LOS “NUEVOS ALIMENTOS” Y LOS “MIEDOS ALIMENTARIOS”. EI caso del pescado}

Hemos dicho ya que los alimentos han cambiado mucho a lo largo de los últimos 40 años. Por definición, las innovaciones alimentarias se caracterizan por diferencias más o menos importantes en relación con los productos conocidos. En esta medida, los nuevos productos pueden suscitar ciertas dudas o problemas y resultan tanto menos tolerables cuanto mayor es la diferencia o distancia con respecto a los productos ya asimilados. Por el contrario, la innovación resulta más aceptada cuanto menor es la diferencia en relación con sistema de representaciones y con la cultura pre-existente. ¿Hasta qué punto los alimentos que hoy consumimos son los mismos que antaño? El caso del pescado constituye otro ejemplo. El pescado no tiene ya la significación sociocultural precisa que tenía antaño. Con respecto al pescado, a lo largo de los últimos años han aparecido diversas innovaciones con diferentes tipos de significación, así como de aceptación o rechazo: congelados, piscifactorías, análogos, funcionales... Así, hoy, los productos del mar están, al igual que otras muchas categorías de alimentos, teñidos de una cierta ambivalencia. ¿Son alimentos naturales o industriales? Hasta cierto punto, nada parecería más natural que un pescado fresco recién pescado. Sin embargo, es sabido que los ríos y los lagos deben ser resembrados, que la pesca en el mar cada vez se parece más a una industria y menos a una actividad artesanal, que la acuicultura no cesa de desarrollarse y que el pescado salvaje cada vez es más escaso. Por otro lado, la contaminación marina y de los ríos, y el riesgo de infecciones bacterianas y víricas, ponen en cuestión la pureza de los productos del mar.

En general, los nuevos productos de pescado han tenido una buena aceptación por parte de los consumidores, incluso superior al de otras innovaciones alimentarias. Además del precio, comparablemente más ventajoso, cabe destacar sus diferentes posibilidades y grados de conveniencia y sin que sus características nutricionales se vean negativamente afectadas, sobre todo en comparación con, por ejemplo, los productos cárnicos o la bollería industrial en torno a los cuales se ha tejido un cierto halo de desconfianza. En efecto, aunque existen algunas diferencias en cuanto a sabor, olor y, sobre todo, textura entre el pescado fresco y el congelado, este último resulta conveniente porque es más barato, su compra no tiene que ser diaria y se cocina más rápidamente e, incluso, puede ya no tener espinas. Todo ello facilita un uso más cotidiano. En este sentido, desde el punto 
de vista de los consumos ordinarios, podría decirse que el pescado congelado ha sustituido a las salazones consumidas tradicionalmente casi a diario. Por otra parte, desde el punto de vista nutricional, razón cada vez más importante, son escasas las diferencias entre el pescado fresco y el congelado.

Asimismo, los productos surimi pueden resultar atractivos para el consumidor actual, puesto que, imitando a otros de mayor prestigio, y de mayor coste, se presentan como una solución de cocina rápida y fácil. En el mundo, son más de un centenar los productos de este tipo usados a diario y siguen anunciándose novedades como el surimi de anchoa o de percebe. Aunque los productos a base de surimi parezcan menos "naturales" que los pescados, su calidad nutritiva es muy satisfactoria. Por cada 100 gramos, contiene: 10,9 gramos de proteínas; de 0,2 a 0,4 de lípidos; de 3 a 6 de glúcidos, y de 1 a 1,4 de sal. Se trata, pues, de un alimento rico en proteínas, bajo en calorías ( $65 \mathrm{kcal}$. $\mathrm{x} 100$ gramos) y barato y que permite aprovechar pescados que nadie querría en su forma natural. Además, como casi nunca se consumen como plato principal, sino como aperitivo o complemento de otros platos, sus posibles deficiencias en algún nutriente se pueden compensar con facilidad por las aportaciones de los otros ingredientes.

Se ha dicho ya que nuestra modernidad alimentaria se caracteriza por la proliferación de los miedos alimentarios y una arraigada sensación de inseguridad en relación con los alimentos que consumimos. Hasta estos momentos, se ha llamado la atención, fundamentalmente, sobre los pesticidas en las legumbres, las hormonas en las carnes, el colesterol en las arterias, la salmonella en el pollo o en los huevos, el prión en las vacas, excesos lipídicos, de sal, azúcar, etc., etc. y todo ello con las temidas consecuencias de obesidad, cánceres de todo tipo, restreñimientos, gastroenteritis, enfermedades cardiovasculares, etc. A la vista de la relación anterior, podría pensarse que los miedos actuales han beneficiado más que perjudicado el consumo de pescado. Hasta cierto punto, es cierto que las crisis alimentarias en relación con los productos cárnicos ("vacas locas", "dioxinas", "peste porcina", etc.) han podido dar lugar a cierto crecimiento, aunque circunstancial y poco perceptible en las series estadísticas, en la demanda de pescado, tanto en lo que se refiere al volumen de ventas como a los precios percibidos.

En definitiva, los pescados, en comparación con otros alimentos, han salido relativamente bien librados en cuanto a estos miedos se refiere. Pero no están exentos. Además de su fragilidad característica y de la histamina que libera con tanta facilidad, otros males, derivados de los modelos intensivos de explotación de los recursos y de la degradación ambiental, empiezan a afectar a los productos del mar. El contenido de mercurio es el más comentado, hasta el punto de que algunos se han preguntado ya si debería limitarse el consumo de pescado como consecuencia de las dosis de mercurio que contiene. El miedo, por el momento al menos, parece no estar justificado al decir de los expertos, pues, si bien es cierto que en dosis altas provoca daños neurológicos, los pescados consumidos tienen cantidades bajas y sin efectos nocivos demostrados. 


\section{R I S}

Hasta el momento, tampoco los pescados han sido asociados con los modelos intensivos de producción alimentaria y su negativa imagen social. Los productos del mar siguen siendo percibidos mayoritariamente como "productos naturales". Sin embargo, esos problemas de imagen asociados con la producción intensiva están empezando a aparecer en la medida en que algunas variedades de pescado son ya más cultivadas que pescadas y que la acuicultura tiene una importancia creciente. Los medios de comunicación informan ya de la utilización de aditivos como, por ejemplo, la caseína en el salmón envasado para mejorar su textura y estructura. Asimismo, el hecho de que las "granjas marinas" hayan empleado piensos a base de harinas cárnicas, al igual que se alimenta a los patos y conejos de otras granjas, puede no beneficiar la imagen de esos pescados hasta ahora muy bien aceptados por los consumidores, pero que podría verse afectada por la misma imagen negativa asociada a los engordes acelerados de otros animales.

Otras particularidades, relativas tanto a la percepción de los productos de pesca como a las inquietudes de determinados movimientos sociales en auge, como los ecologistas, pueden afectar en algún grado la aceptación de los "pescados de cultivo" y del pescado en general, en la medida en que éste se asocie ya definitivamente con la negativamente percibida "industrialización de la alimentación" por el desconocimiento del origen y de las características de los alimentos consumidos. Veamos algunos ejemplos recogidos por la prensa en los últimos años.

\begin{tabular}{l}
\hline "Greenpeace pide que no se den más permisos para el engorde del atún rojo" \\
\hline "La organización ecologista Greenpeace pidió (...) al Gobierno (español) que no conceda más \\
autoriuzaciones para el engorde de atún rojo en granjas flotantes puesto que esa actividad (...) \\
amenaza con provocar el colapso de esa especie (...) Dar de comer hasta 25 kilos de pescado para \\
conseguir tan sólo un kilo de atún es una barbaridad desde el punto de vista ecológico(...)". \\
\hline El Pais, $5-8-2004 ;$ p. 22 \\
\hline
\end{tabular}

"El amargo sabor del langostino tropical. El auge de la acuicultura arrasa los bosques costeros de India o Ecuador y expulsa la población".

\begin{tabular}{l} 
“... la proliferación de piscinas para la cría de este marisco está arrasando los ricos bosques acuáticos \\
costeros (manglares), contaminando el litoral y expulsando a las poblaciones autóctonas en India, \\
Ecuador, Honduras o Tailandia (...) la acuicultura del langostino apareció como una solución a la \\
sobrepesca de arrastre en el mar (...) pero la antigua biodiversidad a base de cangrejos, conchas, \\
camarones y demás especies se ha sustiutido por el monocultivo del langostino en piscinas para la \\
exportación (...). Los grupos ecologistas han pedido a los usuarios que no consuman langostino \\
tropical si desconocen su origen”. \\
\hline La Vanguardia, 5-2-2001; p. 40.
\end{tabular}




\footnotetext{
"Sin denominación de origen. España no aplica normas de la UE que obligan a identificar la procedencia de los alimentos".

\begin{abstract}
"Frente a lo que sucede con los productos elaborados (...) los frescos campean sin pasaporte. En la práctica totalidad de los productos agrícolas y pesqueros, la situación es como una selva. No se conoce su procedencia; no se sabe nada sobre su calidad y frescura. Cuando uno se acerca a una pescadería hay al menos un $50 \%$ de probabilidades de que lo que se está comprando proceda de la importación. En España se comercializan en la actualidad casi una docena de tipos diferentes de merluza según su proecedencia (...). Para una gran mayoría de consumidores es difícil distinguir un pescado de otro hasta que no lo lleva a la cazuela".
\end{abstract}

El Pais, 28-11-1999; p. 30.

Por todo ello, no debe extrañar que, al igual que ocurriera en 1996 con la "ternera gallega", a la que se le expidió carné de identidad para garantizar su cordura, hoy se deba expedir, también, al pescado para conocer su procedencia y su identidad, que también lo es del consumidor:

"iPara saber lo que pescas! Ahora, el pescado tiene DNI. Consulta el nuevo etiquetado informativo que encontrarás en tu pescadería. Con toda la información que necesitas para garantizar la mejor calidad del pescado: el origen, la frescura, la forma de obtención y la presentación. Así siempre sabrás lo que te pescas" [M.A.P.A. Secretaría General de Pesca Marítima (aparecido en El Pais Semanal, 2002)].

\section{LA PARADOJA DE LA SEGURIDAD ALIMENTARIA}

El aumento de la esperanza de vida, la reducción de las influencias religiosas, el mayor desarrollo de los conocimientos científicos y el aumento en la creencia de que "todo se puede conseguir", dan lugar al desarrollo del mito del "riesgo cero". El aumento de los conocimientos científicos (por ejemplo, detectación de nuevos constituyentes patógenos), las mejoras en las técnicas de control y el propio aumento de los controles, permiten una mayor detectación de los constituyentes patógenos. Todo ello da lugar a lo que podría llamarse la paradoja de la seguridad alimentaria: por una parte, el sistema de producción alimentaria se preocupa cada vez más y logra una mayor seguridad y, consecuentemente, los riesgos son cada vez más raros; pero, por otra, la misma escasez de riesgos y su utilización como pretexto proteccionista comporta un fuerte aumento de la mediatización y el aumento de la percepción de los riesgos por parte de la población, sobre todo cuando los efectos de las aplicaciones de las nuevas tecnologías resultan poco conocidos o del todo desconocidos (hormonas, "vacas locas", organismos genéticamente modificados, etc.).

La percepción sobre los riesgos alimentarios se integra y explica en un contexto cultural caracterizado por unos determinados valores sociales y morales, por deter- 


\section{RIS}

minadas concepciones sobre el cuerpo e imagen corporal, por una determinada visión de la enfermedad y de la salud. Aunque se admite que el "riesgo cero" no existe, la capacidad o disposición para asumir riesgos en alimentación es muy inferior que en cualquier otro campo del consumo. Además, los consumidores distinguen diferentes tipos de riesgo: los accidentales y evitables, pero ineludibles en ${ }^{\circ}$ la práctica, y los provocados como consecuencia de prácticas descuidadas, ineficaces o abiertamente fraudulentas y evitables. No se trata, pues, de una incapacidad generalizada por asumir el riesgo, sino una reticencia a asumir riesgos innecesarios y que no conllevan ninguna ventaja aparejada. Se puede estar dispuesto a asumir un riesgo, más o menos incierto, si se perciben ventajas por su utilización. Un producto alimentario sospechoso siempre es sustituible por otro producto alimentario. Es decir, la evitabilidad del riesgo y la posibilidad de sustitución son dos elementos clave a la hora de asumirlo o no.

La industrialización del sector agroalimentario ha ido acompañada de una ruptura fundamental de las relaciones que los seres humanos habían mantenido fisicamente con su medio y con el hecho de que numerosas tareas que hasta entonces eran realizadas por las responsables domésticas en sus cocinas hoy se lleven a cabo en la fábrica (Goody, 1982; Capatti, 1989; Contreras, 1999; Wardle, 1987). La industrialización, percibida en gran medida como una "artificialización" de la alimentación, ha dado lugar a una idea cada vez más persistente, y también más cierta, de que cada vez sabemos menos acerca de lo que comemos. Esta idea o percepción resulta fácilmente aceptable si se tiene en cuenta que los alimentos son cada vez más "procesados", más transformados, de tal modo que la cadena alimentaria es cada vez más compleja y, asimismo, más distante o alejada del ciudadano. Pero, también, y en un sentido muy distinto, la sucesión y la relativa frecuencia de "crisis alimentarias" contribuyen a poner al descubierto aspectos no conocidos, no imaginados y no aceptables en relación con la "manipulación" de los alimentos, pues puede tratarse de aplicaciones tecnológicas cuya existencia y alcance se desconocían previamente: por ejemplo, las vacas comiendo harinas cárnicas elaboradas con los desechos de los propios animales o con restos de ovejas enfermas.

En efecto, en los últimos años, la industria alimentaria ha puesto en circulación una serie de nuevos productos cuyas especiales o novedosas características consisten, fundamentalmente, en alterar su composición y/o su filiación. La ganadería y la avicultura industrial, por ejemplo, ha dado lugar a razas artificiales, aves monstruosas que producen gran cantidad de carne, para conseguir una producción en masa. Las alteraciones pueden consistir en la eliminación de alguno de sus componentes más característicos, por ejemplo la grasa, o en la eliminación de la carne por completo, manteniendo, eso sí, el nombre del producto, el aspecto, el color y alguna referencia a su sabor y a su textura. Podría decirse que la agricultura y la ganadería se alejan, cada vez más, de la naturaleza para acercarse, también cada vez más, al laboratorio y a la industria.Y, también, los "pescados", aunque la palabra pescado tendrá que derivarse sólo de la de "pez" y no de la de "pesca". En 
efecto, especies como la trucha, el salmón, la lubina y el rodaballo ya pueden no ser "pescadas", sino "cultivadas". A estas especies se añadirán otras como, por ejemplo, el atún, pues investigadores japoneses han logrado ya la reproducción del atún en cautividad mediante técnicas de laboratorio. Estos atunes pesan un poco menos que los normales, que a partir de ahora se llamarán "salvajes", pero, por el contrario, son más ricos en grasas, lo que aumenta su valor en el mercado internacional.

De esta manera, los desarrollos recientes de la tecnología o de la industria alimentaria han perturbado la doble función identificadora de lo culinario, es decir, de la identificación del alimento y la construcción o la sanción de la identidad del sujeto (Fischler: 1985, 188). Entre la tecnología, por una parte, y el marketing y la publicidad, por otra, habrían sido destruidas las referencias culturales de la alimentación, es decir, las posibilidades de identificar los alimentos. El alimento se habría convertido en un objeto sin historia conocida y el consumidor moderno no sabría ya qué es lo que realmente está comiendo (Fischler, 1979: 202) pues la industria parece proporcionar (Lambert, 1997) un flujo de "alimentos sin memoria". Así pues, posiblemente nunca como ahora, los consumidores (concepto relativamente nuevo) habíamos sabido tan poco en relación con lo que realmente comemos: embutidos sin carne de cerdo, sucedáneos de angula, de caviar, etc., etc.; animales y plantas modificados genéticamente, productos enriquecidos, ligeros, sin, des, con, inteligentes, energéticos, vacas que no comen hierba, pescado que come piensos cárnicos, nuevos conceptos tales como colesterol, colesterol bueno y colesterol malo, grasas polisaturadas, monoinsaturadas, omega 3, calcio, polifenoles, antioxidantes, flavonoides, bífidos, lactobacilos, etc.etc.

Probablemente, nunca como ahora, la distancia entre el conocimiento científico (aceleradísimo y cambiante) sobre los alimentos (en particular) y sobre la alimentación (las dietas) y el conocimiento popular había sido tan grande en el lenguaje, en el alcance y en las implicaciones de esa distancia y en los nuevos modos en que se atribuyen las responsabilidades: "falta educación nutricional", "falta información", "falta información adecuada", "falta de medidas preventivas", "búsqueda desmesurada del beneficio", etc. Por ejemplo, la conclusión de los autores de un informe ${ }^{3}$ respecto del conocimiento alimentario de la población es que "a pesar de la importancia que se le da, la población presenta un conocimiento bastante mediocre: conocen de manera muy limitada los alimentos que contienen ciertas materias básicas, [y] los beneficios asociados a algunos alimentos importantes de la dieta mediterránea". La opinión mayoritaria de los expertos (tecnólogos, nutricionistas e industriales, sobre todo) coincide con las de este estudio. En efecto, los expertos y los industriales insisten enfáticamente en la falta de formación nutricional de los consumidores y en la importancia que la formación nutricional

${ }^{3}$ ¿A dónde va la alimentación? Estudio de las actitudes hacia la alimentación. IV Foro Internacional de la Alimentación, Barcelona, 2002, p. 205. 
tiene para el desarrollo de una mejor alimentación y una mayor aceptación de los nuevos productos y, concretamente, de los alimentos funcionales.

La inseguridad alimentaria está instaurada en las representaciones sociales de los comedores contemporáneos (Apfelbaum, 1998; Peretti-Watel, 2000 y 2001), aunque las percepciones del riesgo varían sustancialmente dependiendo del contexto en el que se generan. En general, las sucesivas crisis nos permiten poner de manifiesto la dificultad real en establecer los límites entre riesgos reales y riesgos subjetivos. Las personas no dejan de conducir, aunque cada año miles de europeos mueran en las carreteras víctimas de un accidente de coche; pero sí que cuestionan su comida porque asocian riesgos negativos a los alimentos. La contradicción del sistema alimentario moderno entre la abundancia y el riesgo se ha intentado explicar desde diferentes posturas: unas veces argumentando que negarse a la comida es un mecanismo de racionalidad humana, una respuesta ante la abundancia; $y$ otras diciendo que es una expresión de la inseguridad producida por los procesos anómicos que caracterizan nuestro entorno cultural.Ya sea por reacción o por crisis, lo cierto es que estamos ante lo que podemos calificar un nuevo sistema alimentario: el modelo de comportamiento actual ha cambiado sus formas y sus contenidos con respecto a modelos alimentarios anteriores, aunque persistan numerosos elementos inmutables.

La recurrencia de las llamadas crisis, alarmas y escándalos alimentarios ha contribuido a cuestionar de forma creciente los sistemas de prevención de riesgo $\mathrm{y}$, con motivo de esas crisis, se ha producido un rechazo temporal de diferentes tipos de productos alimentarios. Todo ello, a su vez, ha dado lugar a un amplio debate sobre las características de la seguridad alimentaria y las reacciones de los consumidores. En los últimos años, la confianza de los consumidores en la seguridad de los alimentos y en la eficacia de los controles se ha puesto en entredicho. Los recientes escándalos alimentarios han tenido un impacto directo en la competitividad de la industria. Estudios realizados indican que los escándalos pueden tener a largo plazo un efecto significativo en la demanda, así como en la credibilidad de los mecanismos de regulación de las compañías agroalimentarias, en particular cuando, durante los escándalos alimentarios no se dan explicaciones con fundamentación científica o cuando la credibilidad de la institución se pone en entredicho porque se considera que ésta sólo protege sus propios intereses. Todo ello no sólo provoca desconfianza sobre algunos alimentos, sino sobre la totalidad de la cadena alimentaria, científicos y políticos incluidos. Así, la pregunta recurrente de los consumidores es: ¿Qué podemos comer sin miedo?.

El "miedo alimentario" no deja de ser paradójico porque, a lo largo de la historia de los hoy llamados países desarrollados, en ningún otro momento los seres humanos se habían encontrado tan bien, y durante tanto tiempo, como en la actualidad. Las mejoras decisivas aportadas por la higiene y la medicina permiten a una enorme mayoría de la población esperar la tercera edad con una buena salud. A partir de los 65 años, la esperanza de vida es de unos 15 años para los hombres y de 20 para las mujeres. Podría pensarse que ha sido alcanzado ya un 
objetivo vital de la especie y que los progresos futuros en el terreno de la higiene y de la nutrición sólo tendrán unos efectos marginales para la colectividad y su salud. Sin embargo, el aumento del miedo es un hecho social insoslayable que se ha apoderado, incluso, de los espíritus más rigurosos. Se han encontrado nuevos chivos expiatorios en los obesos, los diabéticos o los hipercolesterolímicos. La proporción real de población que constituye los grupos de riesgo alimenta la angustia colectiva. El discurso del miedo es hoy también el discurso del establishment, cuyos actores son tanto los poderes públicos como los dietistas o las empresas. Los medios de comunicación de masas, a su vez, han orquestado magníficamente la puesta en escena y contribuyen a difundir el gran miedo a través de un discurso nutricional que se ha convertido en ideología dominante (Apfelbaum, 1989: 180-181).

\section{CONCLUSIONES}

El reconocimiento fortuito e inesperado del riesgo y su concreción en algo tan cotidiano, frecuente e inevitable como es la comida, especialmente cuando se trata de los alimentos básicos, los más consumidos y los más valorados (carnes, cereales, pescados), se ha traducido de diversas maneras, pues los individuos aprehenden los riesgos según sus valores y sus creencias (Douglas,1996). Así se genera una desconfianza cada vez mayor en la cadena alimentaria. En materia de alimentación, la población no parece querer aceptar riesgos innecesarios y considera poco útiles o poco ventajosas algunas de las aplicaciones de las innovaciones científicas y tecnológicas en el ámbito de la comida: alimentar a las vacas con harinas cárnicas infectadas, aplicaciones tecnológicas orientadas no tanto a mejorar la calidad organoléptica de los alimentos o su valor de salud, sino a facilitar su conservación, transporte, acelerar su maduración o crecimiento, etc.

Asimismo, se desarrolla un escepticismo generalizado frente a la manera de gestionar y resolver políticamente los problemas que atañen al ciudadano más directamente, ya sea en términos de salud, economía o medio ambiente. La desconfianza y el escepticismo social implican un cuestionamiento del modelo científico y de los objetivos de la ciencia, pero sobre todo del modelo de gestión política. Cada controversia alimentaria pone de manifiesto las mismas cuestiones: incertidumbre, ocultación de información, medidas insuficientes, evaluaciones científicas contradictorias. Además, los consumidores no detectan cambios sustantivos en las maneras de actuar y de dar respuesta a los problemas que van surgiendo ni en el modo de informarles o tener en cuenta sus opiniones. Para los expertos, muchas de las crisis alimentarias han sido sỏlo "sustos" más o menos irrelevantes (casos del "aceite de orujo", "vacas locas", "alimentos transgénicos", "pollos con dioxinas", "hormonas de engorde para el ganado"...) en cuanto que el número de personas afectadas y la probabilidad de contraer alguna enfermedad grave o, incluso de morir, ha sido muy baja. Sin embargo, para el común de 
R I S

BEVISTA INTERNACIONAL DE SOCIOLOCIA

№ 40, ENERO-ABRIL, 2005

JESÚS CONTRERAS HERNÁNDEZ

la población, estos problemas acostumbran a tener otra significación. Ponen al descubierto determinados aspectos invisibles de la cadena alimentaria. Ponen al descubierto, también, que, a pesar de que la producción de alimentos está jurídica y científicamente más controlada que nunca, existen fallos importantes en diferentes eslabones de la cadena. La población es sensible a todo este tipo de experiencias, las cuales, a su vez, conforman las representaciones sociales.

\section{REFERENCIAS BIBLIOGRÁFICAS}

ABRAHAMSSON, L. (1979), "The mother's choice of food for herself and her baby", en G. Blix, (ed.), The Mother-Child Dyad: Dietary aspects, Upsala, Alkquist and Wiksells.

APFELBAUM, M. (1989),“La recherche face aux peurs du siècle”, Nourritures. Autrement, vol. 108 , pp.180-184.

(1994), "La diète prudente est-elle bien raisonnable?", Manger magique, Aliments sorciers, croyances comestible, Autrement, vol. 149, pp. 179-183.

APFELBAUM, M. (dir.) (1998), Risques et peurs alimentaires, París, Odil Jacob.

ARIÈS, P. (1997), La fin des mangeurs. Les metamorphoses de la table à l'âge de la modernisations alimentaire, París, Desclée de Brouwer.

ATKINSON, P. (1983), "Eating virtue", en A. Murcott (ed .), The sociology of food and eating. Essays on the sociological significance of food, Hants, Gower Publishing, pp. 9-17.

CAMPION-VINCENT, V. (1994), "La véritable histoire de l'os de rat", Autrement, vol. 149, pp. 84-92.

CAPATTI, A. (1989), Le goût du nouveau. Origines de la modernité alimentaire, París, Albin Michel.

CAZES-VALETTE, G. (1997), "La vache folle", Cultures, nourriture, París, Maison des Cultures du Monde.

CONTRERAS, J. (1999), "Cambios sociales y cambios en los comportamientos alimentarios en la España de la segunda mitad del siglo XX", Anuario de Psicologia, vol. 30 (2), pp. 25-42.

C.R.E.D.O.C. (2002), "Manger est perçu comme présentant davantge de risques“, Consommation et modes de vie, $\mathrm{n}^{\circ} 148$

DOUGLAS, M. (1996), La aceptabilidad del riesgo según las ciencias sociales, Barcelona, Paidós.

FISCHLER, C. (1979), "Gastro-nomie et gastro-anomie: sagesse du corps et crise bioculturelle de l'alimentation moderne", Communications, vol. 31, pp. 189-210. 
(1985), “Alimentation, cuisine et dientité: l'identification des aliments et l'identité du mangeur", Recherches et travaux de l'Institut d'Ethnologie, vol. 6, pp. 171-192.

(1995), "Gastro-nomía y gastro-anomía: sabiduría del cuerpo y crisis biocultural de la alimentacion contemporánea“, en J. Contreras (comp.), Alimentación y cultura: necesidades gustos y costumbres, pp. 357-380.

GOODY, J. (1984), Cuisines, cuisine et classes, París, Centre George Pompidou (Edición española: Cocina, cuisine y clase), Barcelona, (Gedisa).

GRACIA, M. (1996), Paradojas de la modernidad alimentaria, Barcelona, Icaria.

GRACIA, M. (ed.) (2002), Somos lo que comemos, Estudios de alimentación y cultura en España, Barcelona, Ariel.

GRUHIER, F. (1989), "Quand les ingénieurs font la cuisine”, Autrement, vol. 108, pp. 120-124.

GRUGRUNERT, K.G., H. HARTVIG LARSEN, T.K., MADSEN y A. BAADSGAARD (1996), Market Orientation in Food and Agriculture, Boston, Kluwer.

JEGOU, F. (1991), "Nourritures artificielles. Le rôle du design dans l'avenir de l'industrie alimentaire", Programme Alimentation Demain, Ministerio de Agricultura, DCAL-Dâlt, París.

LAMBERT, J.L. (1996), "Les mangeurs entre traditions et nouveautés: quelques specificités du 'marketing alimentaire", en I. Giachetti (ed.), Identités des manguers. Images des aliments, Paris, Polytechnia.

(1997), "Les mangeurs face aux nouvelles technologies alimentaires; conséquences pour les industries alimentaires", Actas coloquio: La conservation de demain, Burdeos.

(1997), "Quelques déterminants socioculturels des consommations de viandes en Europe. La "vache folle» va-t-elle renforcer la tedance à la sarcophagie et au néovégétarisme?", Revue $d u$ Droit Rural, vol. 252, pp. 240-243.

MAHO, J. y P. PINSON, (1989), "Cantines, comment s'en débarrasser?", Autrement, vol.108, pp. 200-204.

MANDERSON, L. (1988), "Suministro de alimentos y cambio social en el sureste asiático y en el Pacífico Sur”, Carencia alimentari, Una perspectiva antropológica ${ }_{\perp}$ pp. 178-202, Barcelona, Ediciones del Serbal.

PERETTI-WETEL, P. (2000), Sociologie du risque, París, Armand Colin.

(2001), La société du risque, París, La decouverte.

POULSEN, C.S., H.J. JUHL, K. KRISTENSEN, A.C., BECH, y E., ENGELUND. (1996), "Quality guidance and quality formation", Food Quality and Preference, vol. 7, pp.127-135. 
RIS

REVISTA INTERNACIONAL DE SOCIOLOGIA

№ 40, ENERO-ABRIL, 2005

JESÚS CONTRERAS HERNÁNDEZ

PYNSON, P. (1989), “Mangeurs fin de siècle”, Autrement, vol. 108, pp. 186-192.

RĖMOND-GOUILLOUD, M. (1997), “Entre ‘bêtises’ et précaution”, Esprit, vol.11, pp. 118-128.

SAVEY, M. (1997), "Les leçons de la 'vache folle”, Esprit, vol. 11, pp. 101-117.

STEEMKAMP, J. (1990), "Conceptual model of the quality perception process", Journal of Bussiness Research, vol. 21, pp. 309-333.

SYLVANDER, B. e I.MELET (1994), La qualité spécifique en agro-alimentaire: marchés, institutions et auteurs, INRA-Toulouse, Serie $\mathrm{P}, \mathrm{n}^{\circ}$ 94-01.

VASSEUR, PH. (1997), La révolution alimentaire. Que mangerons-nous demain?, París, Hachette.

WARDLE, Ch. (1977), Changing food habits in the United Kingdom, Londres, Earth Ressources Research Ltd. 